\title{
Thyroid Eye Disease: How A Novel Therapy May Change The Treatment Paradigm
}

This article was published in the following Dove Press journal:

Therapeutics and Clinical Risk Management

\author{
Yao Wang' \\ Amy Patel (D' \\ Raymond S Douglas ${ }^{1,2}$ \\ 'Department of Surgery, Division of \\ Ophthalmology, Cedars Sinai Medical \\ Center, Los Angeles, CA, USA; ${ }^{2}$ State Key \\ Laboratory of Ophthalmology, Zhongshan \\ Ophthalmic Center, Sun Yat-sen \\ University, Guangzhou, People's Republic \\ of China
}

\begin{abstract}
Thyroid eye disease (TED) is a complex, debilitating autoimmune disease that causes orbital inflammation and tissue remodeling, resulting in proptosis, diplopia, and in severe cases, loss of vision. TED can lead to facial disfigurement and severely impact patients' quality of life. Although the course of TED was identified over 60 years ago, effective treatment options have proved to be challenging. Current treatments such as glucocorticoid therapy and orbital radiation focus on reducing orbital inflammation. However, these therapies fail to modify the disease outcomes, including proptosis and diplopia. Recent advances in the understanding of the molecular basis of TED have facilitated the development of targeted molecular therapies such as teprotumumab, an insulin-like growth factor-1 receptor inhibiting monoclonal antibody. In recent phase 2 and phase 3 randomized placebo-controlled trials, teprotumumab rapidly achieved improvement in clinical endpoints defining TED, including improved proptosis and diplopia. Dramatic improvement in clinical outcomes achieved after teprotumumab therapy during active TED are heretofore singular and comparable only to surgical therapies achieved during the inactive phase of TED. The advent of effective medical therapy can lead to a paradigm shift in the clinical management of TED. This review will provide an overview of TED, its epidemiology, insight into the molecular biology of the disease, clinical characteristics and diagnosis, and current and emerging treatment modalities.
\end{abstract}

Keywords: thyroid eye disease, proptosis, clinical activity score, insulin-like growth factor-1R, teprotumumab

\section{Introduction}

Thyroid eye disease (TED) is a complex autoimmune disease characterized by orbital inflammation (active disease), with subsequent tissue remodeling and fibrosis when the disease becomes inactive. ${ }^{2,3}$ As TED progresses, it leads to proptosis, strabismus, corneal ulceration, and even optic neuropathy. ${ }^{2,4,5}$

Several treatment strategies are available, which focus on immune suppression. ${ }^{1}$ Though some provide short-term relief, they do not necessarily lead to disease course modification. ${ }^{2}$ The management of TED remains a major clinical and therapeutic challenge, as insufficient treatment can negatively impact patients' quality of life (QoL). ${ }^{2,6,7}$ Consequently, there is still an unmet need for an effective disease-modifying treatment with a balanced safety-risk profile. ${ }^{2,8,9}$ This review provides an overview of TED, its epidemiology, molecular biology, clinical characteristics and diagnosis, and current and emerging treatment modalities, including teprotumumab, an insulin-like growth factor-1 receptor (IGF-1R) inhibitor antibody.
Correspondence: Raymond S Douglas Cedars Sinai Medical Center, West Medical Office Towers, $8635 \mathrm{~W}$ Third St, Suite 650W, Los Angeles, CA 90048, USA

Tel + I 310-423-8789

Fax +1 310-248-8596

Email raymonddouglasmd@gmail.com 


\section{Thyroid Eye Disease Epidemiology}

TED is most often associated with Graves' disease (GD), but also can occur in association with hypothyroidism, euthyroidism, and Hashimoto's thyroiditis. ${ }^{1,10-13}$ GD affects approximately $1 \%$ to $2 \%$ of the adult population, ${ }^{8}$ with an estimated $40 \%$ of GD patients subsequently developing TED over the course of their lifetime. ${ }^{14}$ The onset of TED typically occurs between 30 and 50 years of age, with the disease course more severe after age $50 .^{10,15}$

TED often occurs within 18 months following a GD diagnosis. ${ }^{16}$ It can, however, be diagnosed simultaneously or even before the diagnosis of GD. ${ }^{17}$

In Europe, the reported prevalence of active and inactive TED is $10 / 10,000$ individuals. ${ }^{18}$ The only US study on incidence of TED was completed in the 1990s and indicates that the age-adjusted incidence rate for females is 16 cases/100,000 population/year, and 2.9 cases/100,000 population/year for males. ${ }^{19}$ TED is 2.5 - to 6-fold more common among women than men, but is on average, more severe in men. ${ }^{15}$ Active TED is much less prevalent due to its defined disease course and moderate-to-severe TED occurs in less than $5 / 10,000$ individuals. ${ }^{18}$ About $37 \%$ of the overall TED population has active disease at any one time. $^{20}$

\section{Risk Factors}

Untreated thyroid dysfunction (hyper- or hypothyroidism) is associated with the development and progression of TED. ${ }^{21}$ Smoking is the strongest risk factor associated with TED. The risk of developing TED has a greater association with the amount of cigarettes smoked following the diagnosis of GD rather than the cumulative cigarettes smoked. ${ }^{22}$ Further, radioactive iodine, a commonly used treatment for hyperthyroidism, is also a known risk factor for both development and progression of TED. ${ }^{23}$ Concomitant glucocorticoid usage appears to decrease the risk of the development or worsening of TED associated with radioactive iodine therapy. ${ }^{21,24}$

\section{Molecular Biology Of Thyroid Eye Disease}

A complete understanding of the pathophysiology of TED has not been delineated, but evidence suggests that disease pathogenesis is related to loss of self-tolerance to thyroidstimulating hormone receptor (TSH-R) and overexpression of IGF-1R..$^{8,25-27}$ The autoimmune orbital response occurs in TED because of cross-reactivity against antigens that are present in both the thyroid gland and orbital tissue, although the exact pathophysiology is still unclear. ${ }^{11,28}$ It appears that the production of thyroid-stimulating immunoglobulins (TSIs) mimics thyroid-stimulating hormone (TSH), leading to excessive thyroid hormone production and amplified actions on target tissues expressing TSH-R (ie, orbital fat, extraocular muscle, and orbital fibroblasts). ${ }^{25}$ While TSI levels tend to be higher in patients with severe, active TED, a significant correlation between TSI levels and the disease course is lacking. ${ }^{14}$ Therefore, measuring TSI levels is not considered a predictable biomarker to guide the clinical management of TED. ${ }^{14}$

Investigations to determine the underlying cause of TED have recently focused on IGF-1R, as IGF-1R autoantibodies have been detected in GD patients. ${ }^{29}$ IGF-1R, which is overexpressed in TED, forms a physical and functional interactive complex with TSH-R in orbital fibroblasts. ${ }^{27}$ TSH-R and IGF-1R are involved in orbital tissue reactivity and remodeling via production of proinflammatory cytokines and synthesis of hyaluronan (Figure 1). ${ }^{8,25-27,30-32}$ IGF-1R is overexpressed in T cells, B-cells, fibroblasts, myofibroblasts, and fibrocytes in patients with GD. ${ }^{33-36}$ Furthermore, both IGF-1 and Graves' disease-IgG increase hyaluronan concentrations to a similar extent in orbital fibroblasts from GD patients, but not in those from normal controls. These findings indicate an important role for IGF-1R in the pathogenesis of TED. ${ }^{37}$

\section{Clinical Characteristics And Diagnostic Criteria Of Thyroid Eye Disease}

Clinical manifestations of active TED can vary and may include conjunctival chemosis and injection, lid swelling, lid retraction, proptosis, strabismus, exposure keratopathy, and optic neuropathy (Figure 2) ${ }^{38}$ Common symptoms may include eye pain, excessive lacrimation, diplopia, photophobia, and blurry vision. ${ }^{39}$ According to a cohort of patients with TED in Minnesota, eyelid retraction was the most common clinical finding (90.8\% of patients). ${ }^{39}$ Upper eyelid retraction was present in $>70 \%$ of patients, followed by proptosis $(62 \%)$, restrictive myopathy $(43 \%)$, and optic neuropathy $(6 \%){ }^{39}$ Upper eyelid retraction, along with proptosis resulting in lagophthalmos, can cause exposure keratopathy and ulceration. Dysfunction of Bell's phenomenon due to inferior rectus restriction can further worsen corneal exposure. ${ }^{1,40}$ Soft tissue expansion and swelling of the brow fat and the premalar region 


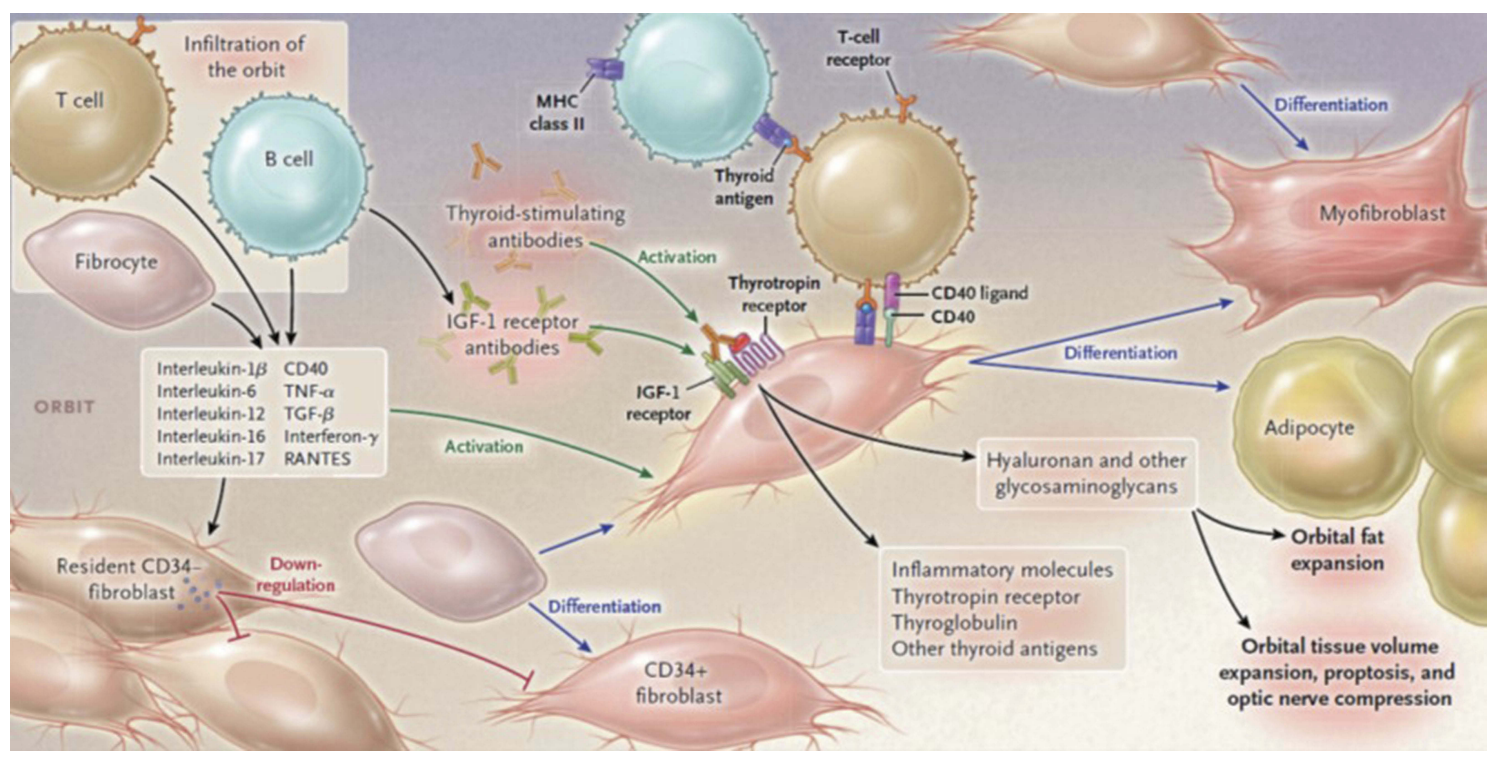

Figure I Pathophysiology of thyroid eye disease. In TED, B-lymphocytes, T-lymphocytes, and CD34+ fibrocytes infiltrate the orbit. CD34+ fibroblasts, originating from bone marrow-derived fibrocytes, further differentiate into myofibroblasts or adipocytes. Both CD34+ and residential CD34- fibroblasts are present within the orbit, and depending upon microenvironment-mediated signaling, can produce cytokines, including IL-I $\boldsymbol{\beta}$, IL-6, IL-8, IL-I6, TNF- $\boldsymbol{\alpha}$, RANTES, and CD40 ligand, which activate orbital fibroblasts. CD34+ fibroblasts express low levels of TSH-R, thyroglobulin, and additional thyroid antigens. TSls activate the TSH-R/IGF-IR complex inducing inflammatory molecule expression and glycosaminoglycan synthesis. Furthermore, immunoglobulins directed against IGF-IR induce orbital fibroblast signaling, thereby increasing cytokine and hyaluronan production, and subsequent orbital tissue expansion, leading to proptosis and compression of the optic nerve. Adipogenesis also leads to orbital fat expansion. From N Engl J Med, Smith TJ, Hegedus L, Graves' disease, 375(16), 1552-1565. Copyright @ (2016) Massachusetts Medical Society. Reprinted with permission from Massachusetts Medical Society. ${ }^{4}$

Abbreviations: IGF-IR, insulin-like growth factor-I receptor; IL, interleukin; MHC, major histocompatibility complex; RANTES, Regulated on Activation, Normal T Cell Expression and Secreted); TED, thyroid eye disease; TGF- $\beta$, transforming growth factor beta; TNF- $\alpha$, tumor necrosis factor alpha; TSH-R, thyroid-stimulating hormone receptor; TSI, thyroid-stimulating immunoglobulins.
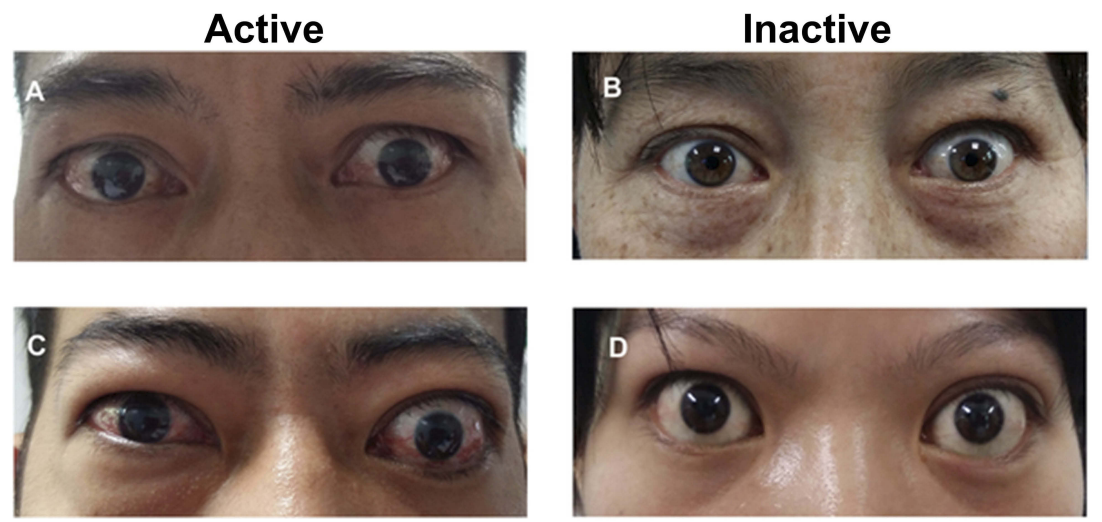

Figure 2 Clinical characteristics of thyroid eye disease. (A) Moderate active TED: lid retraction with evidence of orbital tissue inflammation; (B) Moderate inactive TED: lid retraction; (C) Severe active TED: upper eyelid retraction and binocular soft tissue inflammation; (D) Severe inactive TED: lid retraction with proptosis. Reproduced from Li Q, Ye H, Ding Y, et al. Clinical characteristics of moderate-to-severe thyroid associated ophthalmopathy in 354 Chinese cases. PLoS One. 2017;12(5):e0I76064. Creative Commons License and Disclaimer available from: http://creativecommons.org/licenses/by/4.0/legalcode. ${ }^{38}$

Abbreviation: TED, thyroid eye disease.

can also occur in patients with TED, though with a much lower occurrence rate $(2 \%){ }^{41,42}$

The most feared complication of TED is dysthyroid optic neuropathy. Risk factors include older age, male gender, and smoking. ${ }^{43,44}$ The onset of dysthyroid optic neuropathy can be gradual and subtle, with decreased color vision as the most common presenting feature. Visual field defects may also be present. $^{45}$ A European Group on Graves' Orbitopathy
(EUGOGO) study investigated characteristics of patients with dysthyroid optic neuropathy. ${ }^{46}$ A significant portion of these patients lacked severe inflammation and congestion, as $28 \%$ of patients with TED had a clinical activity score (CAS) of three or less. ${ }^{1,46}$ Therefore, clinical activity score should not be considered as a correlate to optic neuropathy in clinical management, as it can potentially delay treatment. Further, color vision was abnormal in the majority of patients. 
Exophthalmometry was greater than $20 \mathrm{~mm}$ in two-thirds of the patients. Visual field defects included arcuate or altitudinal defects, central/paracentral scotomas, or generalized depression. ${ }^{40}$ Most of these patients had normal appearing optic nerves. ${ }^{46}$ Apical muscle crowding was seen in $88 \%$ of patients with dysthyroid optic neuropathy. ${ }^{46}$ If there is a delay in treatment, patients can develop permanent optic nerve atrophy and irreversible vision loss.

The clinical course of TED frequently follows a pattern first described over 60 years ago by Francis Rundle (Figure 3). ${ }^{47}$ Active TED is an inflammatory, progressive disease characterized by orbital or periorbital inflammation. It generally lasts from 6 to 24 months, but can be present for up to 3 years. The disease then progresses to stable, chronic, fibrotic, inactive disease. Despite reduced inflammation, permanent damage may result and patients do not typically experience significant clinical improvement, responding only to surgery at this point. ${ }^{11}$

Once the patient's disease progresses to inactive TED, their clinical course is typically stable. A small percentage (5-16\%) of patients can experience reactivation of the inflammatory phase, with worsening proptosis as the most common clinical presentation. ${ }^{48,49}$ Risk factors include smoking during initial TED presentation, periocular surgery, pregnancy, and uncontrolled hypo- or hyperthyroidism. ${ }^{48-51}$

Various outcome assessment scales are used in clinical trials, and to a lesser extent in practice, to evaluate effectiveness of therapies for TED. ${ }^{1} \mathrm{CAS}$ assesses the presence of inflammatory symptoms and was initially developed to identify active inflammation to help predict glucocorticoid therapy response (Table 1). ${ }^{16}$ It is used to help identify active TED patients and document their response to treatment over time. ${ }^{52}$ A list of seven inflammatory orbital
Table I Clinical Activity Score ${ }^{a}$

\begin{tabular}{|c|c|}
\hline CAS & For initial assessment, only score items I-7 \\
\hline I & Spontaneous orbital pain \\
\hline 2 & Gaze evoked orbital pain \\
\hline 3 & Eyelid swelling; considered due to active TED \\
\hline 4 & Eyelid erythema \\
\hline 5 & Conjunctival redness; considered due to active TED \\
\hline 6 & Chemosis \\
\hline \multirow[t]{2}{*}{7} & Inflammation of caruncle or plica \\
\hline & $\begin{array}{l}\text { Follow-up assessment at I-3 months can be scored } \\
\text { out of } 10\end{array}$ \\
\hline 8 & Increase of $>2 \mathrm{~mm}$ in proptosis \\
\hline 9 & $\begin{array}{l}\text { Decrease in uniocular excursion in any one direction of }>8 \\
\text { degrees }\end{array}$ \\
\hline 10 & Decreased acuity equivalent to I Snellen line \\
\hline
\end{tabular}

Note: One point is given for the presence of each parameter. Clinical activity is defined as the sum of all the points. Active ophthalmopathy is considered if the initial assessment is $\geq 3 / 7$, or follow-up assessments are $\geq 4 / 10$. ${ }^{2} A$ mended by EUGOGO. Modified from. Modified from Barrio-Barrio J, Sabater AL, Bonet-Farriol E, Velazquez-Villoria A, Galofre JC. Graves' ophthalmopathy: VISA versus EUGOGO classification, assessment, and management. J Ophthalmol. 2015;2015:249125. Creative Commons License and Disclaimer available from: http://creativecommons.org/licenses/by/4.0/legalcode. ${ }^{52}$

Abbreviations: CAS, clinical activity score; EUGOGO, European Group of Graves' Orbitopathy; TED, thyroid eye disease.

symptoms representing pain, redness, and swelling constitute the CAS with the presence of three or more indicating the patient is active. ${ }^{52}$ The list can be expanded to 10 symptoms for follow-up. ${ }^{52}$ There are several classification systems in rather limited use (eg, NOSPECS [No physical signs or symptoms, Only signs, Soft tissue involvement, Proptosis, Extraocular muscle signs, Corneal involvement, and Sight loss; Table 2], VISA [Vision, Inflammation, Strabismus, and Appearance], and EUGOGO). ${ }^{11,52}$

In clinical practice, TED is generally diagnosed via a combination of medical history, presenting symptoms, radiographic imaging, and laboratory results (eg, TSH, TSI,

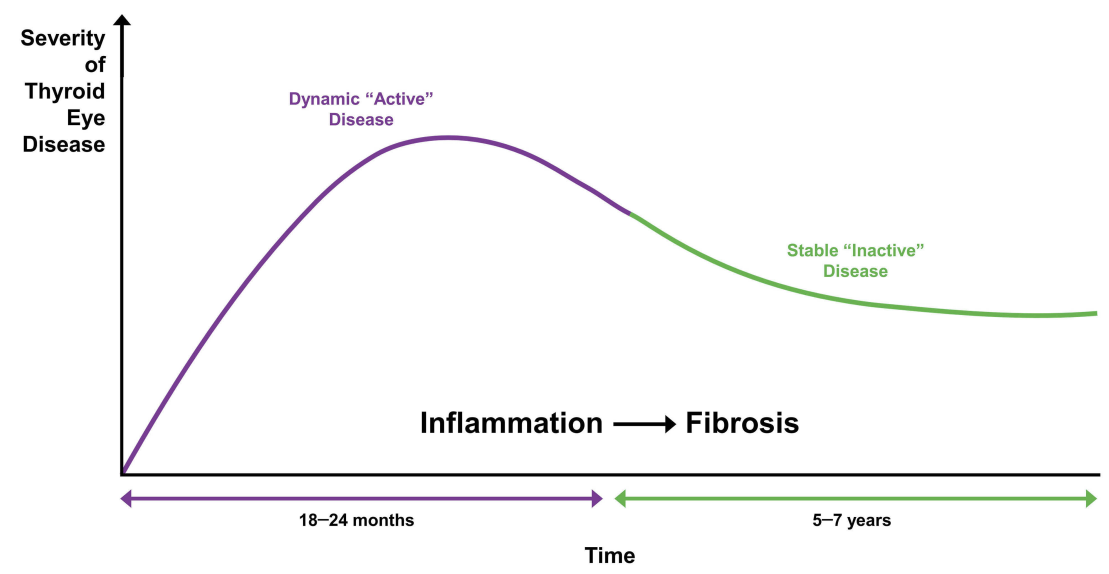

Figure 3 An approximation of a curve depicting severity of thyroid eye disease over time that is based on a concept by Rundle. ${ }^{10}$ 
Table 2 NOSPECS Classification

\begin{tabular}{|l|l|}
\hline SCORE & Classification \\
\hline 0 & No signs or symptoms are present \\
1 & Only signs, but no symptoms are present \\
2 & Soft tissue is involved, with signs of swelling and redness \\
3 & Proptosis \\
4 & Extraocular muscle involvement \\
5 & Corneal involvement, punctate keratopathy, and \\
6 & ulceration \\
& Sight loss; changes occur in visual acuity, color vision, and \\
& visual field \\
\hline
\end{tabular}

Note: Adapted from Bothun ED, Scheurer RA, Harrison AR, Lee MS. Update on thyroid eye disease and management. Clin Ophthalmol. 2009;3:543-55I. doi:I0.2I47/ opth.s5228. Creative Commons License and Disclaimer available from: http://creative commons.org/licenses/by/4.0/legalcode. "

Abbreviations: NOSPECS, No physical signs or symptoms, Only signs, Soft tissue involvement, Proptosis, Extraocular muscle signs, Corneal involvement, and Sight loss.

thyroid peroxidase antibody, and TSH-R antibody levels). ${ }^{1,11}$ However, not every clinician chooses the same combination of diagnostic tools, and there continues to be a lack of standardization. Improved assessment techniques in the future may be beneficial to better guide clinicians. ${ }^{16}$

\section{Treatment Modalities For Thyroid Eye Disease}

Treatment options for TED generally depend on disease activity and severity (Table 3). ${ }^{1,53}$ Active and inactive TED can vary in severity, typically described as mild, moderate-to-severe, or sight-threatening. ${ }^{1}$ In active, mild TED, ocular lubricants, sunglasses, and prisms are used for supportive management. ${ }^{10,53}$ For active, moderate or severe disease, a variety of treatment strategies are used, sometimes resulting in short-term relief. However, there is still an unmet need for disease-modifying treatments with an optimal safety profile and long-term benefits. ${ }^{1,2}$

\section{Orbital Radiation}

Orbital radiation (OR) has been used for the treatment of TED for several decades, and is generally well-tolerated. ${ }^{54}$ The rationale for its use is two-fold. The first lies in its nonspecific anti-inflammatory effect, and the second is the radio-sensitivity of orbit-infiltrating lymphocytes. ${ }^{54,55}$ Additionally, OR may target fibroblasts leading to reduced glycosaminoglycan synthesis and secretion. ${ }^{56}$

However, due to non-standardized protocols and relative lack of randomized clinical trial results, the use of $\mathrm{OR}$ is not without controversy. Three randomized clinical trials found differing results. While Gorman et al did not find a difference between OR and sham therapy, ${ }^{57}$ Mourits et al found OR to be superior to sham. ${ }^{58}$ Prummel et al found OR to be effective in reducing diplopia and improving extraocular muscle motility in patients with mild TED, although there was no effect on QoL or disease progression. ${ }^{59}$ Further studies evaluating concomitant OR with intravenous (IV) or oral glucocorticoids also yielded dissimilar results. ${ }^{60-63}$ A report from the American Academy of Ophthalmology concluded that there is considerable heterogeneity and variability in the quality of studies assessing the benefit of OR for the treatment of TED. ${ }^{64}$ Overall, OR appears to offer little, if any, long-term clinical benefit.

\section{Immunosuppression \\ Glucocorticoids}

In Europe, glucocorticoids are considered the first-line treatment for active TED to reduce edema and orbital inflammation, as recommended by the EUGOGO guidelines. ${ }^{1}$ IV pulse glucocorticoid administration is preferred to oral administration, as it has a more favorable efficacy and safety profile. ${ }^{8,10}$ However, high-dose systemic glucocorticoid therapy can have undesired adverse effects, including the development of Cushingoid features, hypertension, hyperglycemia, mood instability, weight gain, and osteoporosis. ${ }^{10}$ Although glucocorticoids are frequently used in the treatment of TED, their therapeutic efficacy has not been confirmed by adequate placebo-controlled trials to date. ${ }^{14}$ In a study investigating three cumulative IV doses of methylprednisolone ( $2.25 \mathrm{~g}, 4.98 \mathrm{~g}$, and $7.47 \mathrm{~g}$ ) in patients with active, moderate-to-severe TED, the $7.47 \mathrm{~g}$ dose (over a 12-week period) reduced CAS and mildly improved ocular motility. ${ }^{65}$ However, it did not improve proptosis or diplopia significantly and was associated with significant adverse events (AEs), such as diabetes mellitus, psychosis, and depression. ${ }^{65}$ Furthermore, the only placebo-controlled trial showed that methylprednisolone pulse therapy did not significantly improve mean proptosis or diplopia. ${ }^{66}$ Diplopia improved in 50\% (2/4) of methylprednisolone-treated patients compared with $0 \%(0 / 5)$ of placebo-treated patients, although the improvement was not statistically significant $(\mathrm{P}=0.073)$. Proptosis improved in $40 \%(2 / 5)$ of methylprednisolone-treated patients and in $29 \%(2 / 7)$ of placebo-treated patients, which was also not statistically significant $(\mathrm{P}=0.68) .{ }^{66}$

Periocular and orbital glucocorticoid administration are alternative proposed treatment options that can limit systemic side effects. A multicentered, randomized, controlled study found that patients who received four inferolateral orbital injections of $20 \mathrm{mg}$ of triamcinolone 
Table 3 Current And Emerging Therapies For Thyroid Eye Disease

\begin{tabular}{|c|c|c|c|}
\hline Therapy & Mode Of Action & Pros And Cons & Common Doses \\
\hline \multicolumn{4}{|c|}{ Active, mild disease: } \\
\hline \multicolumn{4}{|l|}{ Topical solutions } \\
\hline Artificial tears & Maintains tear film & Rapid action, minimal side effects & \\
\hline Glucocorticoids & Reduces inflammation & Rapid action, minimal side effects & \\
\hline Selenium & Uncertain & Benefits not yet confirmed & \\
\hline \multicolumn{4}{|c|}{ Active, moderate-to-severe disease: } \\
\hline \multicolumn{4}{|l|}{$\begin{array}{l}\text { Systemic } \\
\text { glucocorticoids }\end{array}$} \\
\hline Oral & $\begin{array}{l}\text { Reduces inflammation } \\
\text { and orbital congestion }\end{array}$ & Hyperglycemia, hypertension, osteoporosis & $\begin{array}{l}\text { Up to } 100 \mathrm{mg} \text { of oral prednisone } \\
\text { daily, followed by tapering of the } \\
\text { dose }\end{array}$ \\
\hline Intravenous & $\begin{array}{l}\text { Reduces inflammation } \\
\text { and orbital congestion }\end{array}$ & $\begin{array}{l}\text { Rapid onset of anti-inflammatory effect, fewer side } \\
\text { effects than oral delivery, liver damage on rare } \\
\text { occasions }\end{array}$ & $\begin{array}{l}\text { Methylprednisolone, } 500 \mathrm{mg} / \text { week } \\
\text { for } 6 \text { weeks followed by } 250 \mathrm{mg} / \\
\text { week for } 6 \text { weeks }^{65,112}\end{array}$ \\
\hline Orbital irradiation & Reduces inflammation & Can induce retinopathy & 2 Gy daily for 2 weeks ( 20 Gy total) \\
\hline Rituximab ${ }^{a}$ & $\begin{array}{l}\text { Reduces autoreactive B- } \\
\text { cells }\end{array}$ & $\begin{array}{l}\text { Very expensive; risks of infection, cancer, allergic } \\
\text { reaction }\end{array}$ & $\begin{array}{l}2 \times 1000 \mathrm{mg} \text { doses of intravenous } \\
\text { rituximab } 2 \text { weeks apart }\end{array}$ \\
\hline Teprotumumab & Targets IGF-IR & $\begin{array}{l}\text { Reduced proptosis and diplopia, comparable to } \\
\text { surgery }\end{array}$ & $\begin{array}{l}8 \text { intravenous infusions (starting dose } \\
\text { of } 10 \mathrm{mg} / \mathrm{kg} \text {; followed by } 20 \mathrm{mg} / \mathrm{kg} \text { ) }\end{array}$ \\
\hline Tocilizumab $^{\mathrm{a}}$ & Targets IL-6 & Did not reduce proptosis ${ }^{102}$ & $\begin{array}{l}8 \mathrm{mg} / \mathrm{kg} \text { every } 4 \text { weeks for } 12 \\
\text { weeks }^{102}\end{array}$ \\
\hline Adalimumab $^{\mathrm{a}}$ & Targets TNF- $\alpha$ & $\begin{array}{l}\text { Subjective improvement in diplopia, pain, and swelling; } \\
\text { no significant changes in proptosis or extraocular } \\
\text { movement restriction }\end{array}$ & $\begin{array}{l}10 \text { weeks of treatment ( } \mathrm{I} \text { injection of } \\
80 \mathrm{mg} \text {; followed by } 40 \mathrm{mg} \text { injection } \\
\text { twice/week) }\end{array}$ \\
\hline $\begin{array}{l}\text { Emergency orbital } \\
\text { decompression }{ }^{\mathrm{b}}\end{array}$ & Reduces orbital volume & & \\
\hline \multicolumn{4}{|c|}{ Inactive (stable) disease } \\
\hline $\begin{array}{l}\text { Orbital } \\
\text { decompression } \\
\text { (fat removal) }\end{array}$ & Reduces orbital volume & Postoperative diplopia, pain & \\
\hline $\begin{array}{l}\text { Bony } \\
\text { decompression of } \\
\text { the lateral and } \\
\text { medial walls }\end{array}$ & $\begin{array}{l}\text { Reduces proptosis by } \\
\text { enlarging orbital space }\end{array}$ & $\begin{array}{l}\text { Postoperative diplopia, pain, sinus bleeding, } \\
\text { cerebrospinal fluid leak }\end{array}$ & \\
\hline Strabismus repair & Reduces diplopia & & \\
\hline Eyelid repair & $\begin{array}{l}\text { Improves appearance, } \\
\text { reduces lagophthalmos, } \\
\text { improves function }\end{array}$ & & \\
\hline
\end{tabular}

Notes: Data from Smith et al, 2016. ${ }^{4}$ a Currently considered an experimental treatment for ophthalmology; not approved by the United States Food and Drug Administration for this indication. ${ }^{b}$ Emergency orbital decompression is indicated for optic neuropathy or severe corneal exposure.

Abbreviations: IGF-IR, insulin-like growth factor-I receptor; IL, interleukin; TNF- $\alpha$, tumor necrosis factor alpha. 
acetate $40 \mathrm{mg} / \mathrm{mL}$ ( 24 patients vs 17 patients in the control group) experienced improvement in diplopia, with radiographic imaging showing a reduction in the size of extraocular muscles. ${ }^{67}$ Although patients also reported fewer side effects, these treatments failed to demonstrate consistent efficacy. Larger trials are needed to fully evaluate the efficacy of locally administered glucocorticoids. ${ }^{67}$

\section{Mycophenolate}

Mycophenolate mofetil (MMF), an immunosuppressant, is converted to mycophenolic acid (MPA) via the action of hepatic esterase and inhibits guanosine monophosphate synthesis (de novo purine synthesis). ${ }^{68,69}$ MPA potently inhibits the type 2 isoform of inosine monophosphate dehydrogenase, thereby inhibiting lymphocyte proliferation. ${ }^{68,70}$ This immune modulatory effect led to the evaluation of MPA for the treatment of TED. ${ }^{68-70}$

The safety of MPA in patients with active, moderateto-severe TED was evaluated in a prospective longitudinal study over 24 weeks, with concomitant intravenous steroids during the first 12 weeks. ${ }^{68}$ AEs were reported in $68 \%$ (36/53) of patients. ${ }^{68}$ Serious AEs were reported in $13 \%$ (7/53) of patients, but none were considered treatmentrelated. $^{68}$

Mycophenolate was subsequently evaluated in combination with methylprednisolone in active, moderate-tosevere TED in a randomized, observer-masked, multicenter, open-label 36 -week trial. ${ }^{70}$ The primary outcome was not met, although statistically significant improvements were noted in the methylprednisolone plus mycophenolate groups at both 24 and 36 weeks in post hoc analyses. ${ }^{70}$ Overall, cumulative results suggest that MMF may be a well-tolerated option to treat TED, but it appears to offer minimal long-term benefit. ${ }^{69}$

\section{Cyclosporine}

Cyclosporine, alone or in combination with glucocorticoid therapy, has been proposed as an effective treatment for TED. ${ }^{71,72}$ A randomized controlled trial compared cyclosporine plus prednisone to prednisone only for 10 weeks. $^{72}$ A greater improvement in CAS and visual acuity were observed with combination therapy at 10 weeks when compared with prednisone monotherapy at 10 weeks $(\mathrm{P}<0.001$ and $\mathrm{P}<0.01$, respectively). ${ }^{72}$ However, after 10 weeks, there were no significant improvements in proptosis, CAS, or visual acuity. Moreover, relapses occurred in $40 \%(8 / 20)$ of patients in the prednisone group during the following 6 months and in $5 \%(1 / 20)$ in the combined treatment group at 9 months. ${ }^{72}$ AEs included increased liver enzymes and hypertension. ${ }^{72}$ In another study, the response in total eye score after 12 weeks with prednisone alone was $61 \%(11 / 18)$ as compared with $22 \%(4 / 18)$ for the cyclosporine only group $(\mathrm{P}=0.018) .{ }^{71}$ However, neither group had significant improvement in proptosis or eye muscle score. ${ }^{71}$ Patients in both groups who did not respond received combination therapy of cyclosporine and a low dose of prednisone for an additional 12 weeks and overall response was improved in some patients. Again, there was no consistent benefit in mean proptosis or eye muscle score from 12 to 24 weeks. ${ }^{71}$ Therefore, cyclosporine may offer improved anti-inflammatory potential, but there is no data to suggest long-term clinical improvement in proptosis or strabismus.

\section{Others}

Studies have shown that high dose IV immunoglobulin is as effective as high doses of oral glucocorticoids. ${ }^{73,74}$ However, this is not routinely used today for the treatment of TED. Other immunosuppressive medications, such as somatostatin analogues, azathioprine, and ciamexone have, in aggregate, been found ineffective in the treatment of TED. ${ }^{75-80}$

\section{Surgical Management Of Thyroid Eye Disease}

Surgical intervention for TED is typically a multi-staged approach of sequential orbital decompression, eye muscle surgery, and/or eyelid surgery. ${ }^{1}$ Most patients with TED will not require surgical intervention, with previous reports showing that $20 \%$ of patients undergo $\geq 1$ surgical procedures. ${ }^{81}$ The probability of undergoing surgery was $5 \%$ at 1 year after diagnosis, $9.3 \%$ at 2 years, $15.9 \%$ at 5 years, and rose to $21.8 \%$ at 10 years. ${ }^{81}$ Up to $27 \%$ of patients are offered surgery after the disease becomes inactive. ${ }^{20}$ The need for surgical intervention increased with age, with patients aged $\geq 50$ years having a 2.6 -times greater risk. ${ }^{81}$

Surgical decompression is generally performed on TED patients with inactive stable disease, but also can be used for active patients when vision is threatened by compression optic neuropathy. ${ }^{11,16}$ The orbital surgeon may decide to perform fat decompression as well as bony decompression. ${ }^{1}$ In general, between $5 \%$ and $20 \%$ of TED patients will undergo decompression surgery. ${ }^{82}$ Unfortunately, orbital surgery can reactivate inflammation, exacerbating ophthalmopathy, and orbital decompression can cause strabismus in one-third of patients. ${ }^{2,83}$ 
The enlargement and fibrosis of extraocular muscles in TED can cause restrictive strabismus and diplopia, which can significantly affect QoL. ${ }^{84}$ The inferior and medial recti muscles are most commonly affected. Strabismus surgery is typically performed following orbital decompression, due to the risk of worsening of diplopia. ${ }^{1}$ The primary goal of strabismus surgery is for binocular vision in primary gaze and down gaze, and secondarily to improve the window of single binocular vision. ${ }^{85}$ The typical surgical plan includes recession of the restricted muscle. It is important to discuss expectations, as patients may need additional strabismus surgery or require the aid of prisms.

Upper eyelid retraction is the most common feature of TED. ${ }^{86}$ Its pathophysiology includes GD-induced sympathetic excess and eyelid fibrosis. Upper eyelid retraction, along with proptosis, can cause exposure keratopathy and ulceration due to lagophthalmos. There are various techniques to correct upper eyelid retraction, including graded müllerectomy or full thickness blepharotomy. ${ }^{87,88} \mathrm{Good}$, predictable results have been achieved with these different procedures, and treatment decision is ultimately guided by surgeon preference and experience.

Similarly, lower eyelid retraction is theorized to be caused by sympathetic overstimulation and fibrosis. ${ }^{89} \mathrm{~A}$ transconjunctival approach is typically favored, in which the lower eyelid retractors are recessed or separated. Spacer grafts (homologous, autologous, or alloplastic material) can be used if the retraction is severe. ${ }^{90,91}$

\section{Smoking Cessation}

As previously mentioned, cigarette smoking is a significant risk factor for the development and progression of TED. ${ }^{92}$ Microarray analysis of intra-orbital fat from both smokers and nonsmokers with active TED revealed differences in gene expression, including 103 genes that were upregulated and 54 genes that were downregulated. ${ }^{93}$ In particular, $I L-1 \beta$ and $I L-6$ expression were upregulated 2.3-fold $(\mathrm{P}=0.03)$ and 2.4-fold $(\mathrm{P}=0.004)$, respectively, in intraorbital fat from smokers with TED compared with their nonsmoker counterparts. ${ }^{93}$

A prospective study demonstrated the negative impact of smoking on the treatment response following OR or glucocorticoid therapy in patients with active, moderate TED. A greater number of nonsmokers had improved motility $(60 \%$ vs $24 \%$, P $<0.017)$ and reduction in CAS compared with smokers after 12 months $(\mathrm{P}<0.05) .{ }^{22}$ However, no significant changes were observed in proptosis after 12 months. ${ }^{22}$ Patients should be advised that smoking exacerbates the severity of ophthalmopathy and lessens the response to treatment. ${ }^{94}$

\section{Selenium}

Selenium was evaluated as a therapeutic option in a randomized, double-blind, placebo-controlled trial in euthyroid patients with mild TED. ${ }^{95}$ Patients were treated with $100 \mu \mathrm{g}$ sodium selenite twice per day for 6 months with an additional 6-month follow-up period. ${ }^{95}$ The selenium-treated patients had a significant improvement in QoL and CAS, compared with placebo at 6 and 12 months $(\mathrm{P}<0.001)$. Symptomatic improvement was observed in $61 \%(33 / 54)$ of the selenium-treated patients compared with $36 \%(18 / 50)$ of the placebo group. ${ }^{95}$ Furthermore, only 7\% (4/54) of patients in the selenium group had disease progression, compared with $26 \%(13 / 50)$ in the placebo group. ${ }^{95}$ Selenium was not associated with any AEs. ${ }^{95}$ However, no significant changes in proptosis at 6 or 12 months were reported. ${ }^{95}$ Limitations of this study included the lack of serum selenium assessment at baseline and throughout the study. ${ }^{95}$ Since most patients originated from areas where the general population has marginally reduced selenium levels, a slight selenium deficiency may have confounded a beneficial effect upon supplementation. ${ }^{95}$ The reported beneficial effects of selenium have not been demonstrated in a selenium-rich or nondeficient population to date.

\section{Others}

Other antioxidants, such as allopurinol and nicotinamide, have been suggested to improve visual acuity, reduce differential pressure, and improve ocular motility in patients with TED. However, there is insufficient clinical data to demonstrate benefits or efficacy. ${ }^{96,97}$ These antioxidants are not routinely used in clinics and are not approved for treatment of TED.

\section{Novel, Targeted Biological Therapies}

\section{Thyroid-Stimulating Hormone Receptor Inhibitors}

Antibodies that inhibit the TSH-R are under consideration as potential treatment options for TED. ${ }^{25}$ An array of small-molecule TSH-R antagonists have been tested in vitro and in vivo in preclinical models, but no robust clinical trials have been conducted to date. ${ }^{25}$

\section{Tocilizumab}

Tocilizumab, an IL-6 receptor monoclonal antibody, is approved for the treatment of active, moderate-to-severe rheumatoid arthritis and giant cell arteritis and is under 
consideration as a potential treatment for TED. ${ }^{9,98,99}$ IL-6 is a proinflammatory cytokine produced by a variety of cells, including fibroblasts, monocytes, and $\mathrm{T}$ and $\mathrm{B}$ lymphocytes, which are implicated in the disease process of TED. ${ }^{9}$ It is found in high concentrations in the serum of patients with TED100 A small study showed that tocilizumab reduced inflammation in patients who were unable to tolerate glucocorticoids. ${ }^{101}$ A more recent randomized clinical trial (NCT01297699) showed that $93.3 \%$ of patients treated with tocilizumab vs $58.8 \%$ receiving placebo met the primary endpoint of reduction of CAS by $\geq 2$ points at week $16(\mathrm{P}=0.04$; odds ratio, $9.8 ; 95 \%$ confidence interval [CI] 1.3-73.2) ${ }^{102}$ However, tocilizumab did not significantly improve diplopia. In addition, although tocilizumab significantly improved median proptosis at week 16 compared with placebo $(\mathrm{P}=0.003)$, the magnitude of the reduction from baseline was only 1.5 $\mathrm{mm}$, which may not be a clinically significant reduction. ${ }^{102}$ At week 40, 93 AEs were reported among 27 patients; the most common being headache (11 tocilizumab vs 4 placebo) and infections (17 vs 7). There were serious AEs in 2 patients receiving tocilizumab (one with a moderate increase in transaminase levels, attributed to latent tuberculosis, and another with acute pyelonephritis). ${ }^{102}$

\section{Anti-tumor Necrosis Factor-Alpha Agents}

In a small retrospective, off-label study, there was subjective improvement in diplopia, pain, and swelling in $40 \%(4 / 10)$ of patients; following 3 months of adalimumab therapy (an initial injection of $80 \mathrm{mg}$ followed by $40 \mathrm{mg}$ injections twice per week). However, there were no significant improvements in proptosis or extraocular movement restriction. ${ }^{103}$ A case report showed that an infliximab infusion improved symptoms (pain related to corneal exposure and ocular movement), visual acuity, color vision, and CAS. ${ }^{104}$ While these findings suggest that anti-tumor necrosis factor-alpha agents may benefit some TED patients, larger studies are needed to confirm their efficacy and safety. ${ }^{105}$

\section{Rituximab}

Rituximab is a chimeric monoclonal antibody targeting CD20, a membrane-embedded protein expressed on the surface of pre-B and mature B lymphocytes. ${ }^{106}$ Since rituximab depletes CD20-carrying B-cells, it was proposed as a potential treatment for TED. ${ }^{8}$ Two small controlled trials were conducted to evaluate the efficacy of rituximab, ${ }^{80,107}$ with inconsistent results. In one study, rituximab $(500 \mathrm{mg}$ or $2000 \mathrm{mg}$ ) and IV methylprednisolone (7.5 g) both decreased CAS (more pronounced in the rituximab group compared to IV methylprednisolone at 16, 20, and 24 weeks). ${ }^{107}$ After 24 weeks, 15/15 (100\%) patients on rituximab improved (decrease of $\geq 2$ points in CAS and CAS $<3)$, compared with 11/16 (69\%) patients with CAS $<3$ $(\mathrm{P}<0.05)$ and $12 / 16(75 \%)$ with a CAS decrease by $\geq 2$ points (NS) in the IV methylprednisolone group. ${ }^{107}$ However, none of the patients receiving rituximab had $\geq 2$ $\mathrm{mm}$ reductions in proptosis at week $24 .{ }^{107}$ In the second study, 25 patients were administered 2 infusions of rituximab (1000 mg each) or IV normal saline 2 weeks apart. ${ }^{80}$ At 24 and 52 weeks, rituximab did not significantly improve CAS, proptosis, diplopia, or QoL, and did not reduce orbital fat/muscle volume. ${ }^{80}$ In summary, rituximab was associated with AEs and has shown no benefits over placebo with respect to the major serious outcomes of TED, such as proptosis and diplopia. ${ }^{80}$

\section{Teprotumumab}

Teprotumumab, an IGF-1R inhibitory antibody, binds with high affinity and specificity to IGF- $1 \mathrm{R},{ }^{35}$ inducing internalization and degradation of the antibody-receptor complex. ${ }^{14}$ In vitro studies show that IGF-1R and TSH-R form a physical complex. ${ }^{2,27,35}$ Production of proinflammatory cytokine (eg, IL-6 and IL-8) is increased via IGF-1R/TSH-Rmediated activation of fibroblasts. ${ }^{35}$ In vitro studies showed that teprotumumab attenuates such TSH-mediated cytokine production by reducing IGF-1R and TSH-R cell surface expression. ${ }^{35}$ Moreover, teprotumumab inhibits IGF-1 and TSH-mediated Akt phosphorylation, thereby attenuating IGF-1R and TSH-R-mediated signaling. ${ }^{35}$ Therefore, teprotumumab reduces hyaluronan production and cytokine stimulation in orbital fibroblasts, ${ }^{32,35}$ leading to reduced intraorbital hyaluronan accumulation and reduced adipogenesis and muscle expansion (Figure 4). ${ }^{2}$

The phase 2 multicenter, double-masked, placebo-controlled, randomized clinical trial (NCT01868997) evaluating the efficacy and safety of teprotumumab enrolled 88 patients with recent onset, active, moderate-to-severe TED. ${ }^{108}$ Patients were randomized $(1: 1)$ to receive teprotumumab or placebo. ${ }^{108}$ Patients received a total of 8 infusions over the 24-week observation period, with 1 IV infusion every 3 weeks, (first dose: $10 \mathrm{mg}$ per kg; subsequent doses: $20 \mathrm{mg}$ per $\mathrm{kg}$; last dose at week 21). ${ }^{108}$ The primary endpoint was a decrease in CAS of $\geq 2$ points and a reduction in proptosis of $\geq 2 \mathrm{~mm}$, without an equal deterioration in the nonstudy eye. ${ }^{108}$ The teprotumumabtreated patients improved significantly compared with the 
A.

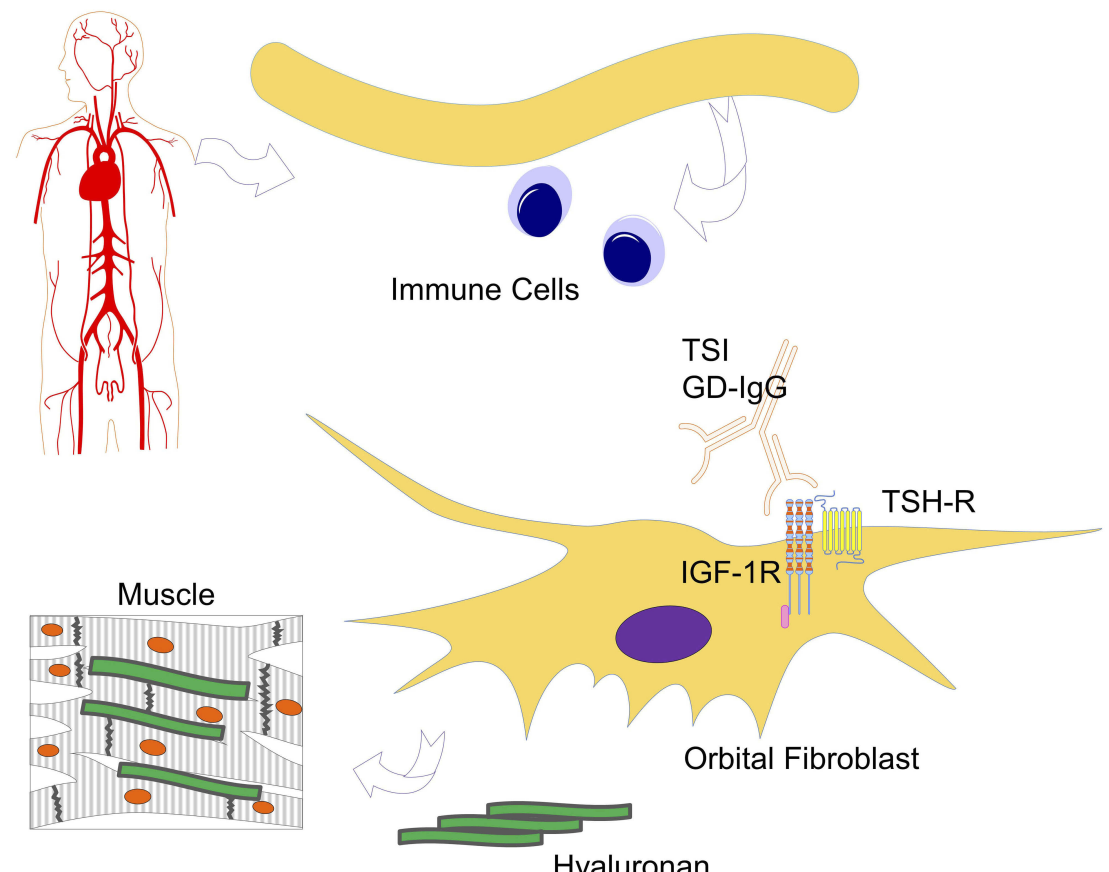

Hyaluronan

B.

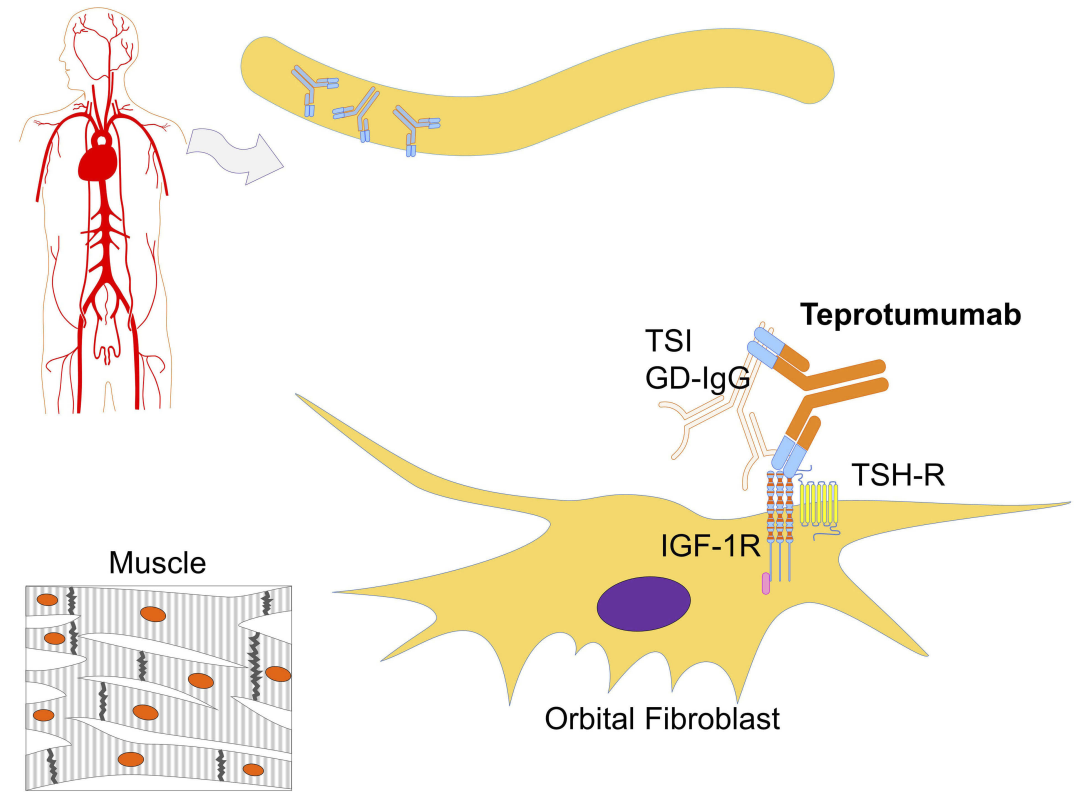

Figure 4 Mechanism of action of teprotumumab. (A) Evidence suggests that TED occurs due to upregulation of the TSH-R/IGF-IR complex consequential to pathogenic autoantibody (GD-lgG and TSI) stimulation of fibroblasts. Such activation leads to the production of glycosaminoglycans (eg, hyaluronan), and expansion of fat and muscle next to the eye. ${ }^{2}$ (B) Teprotumumab attenuates pathogenic autoantibody-mediated stimulation of orbital fibroblasts, thereby inhibiting TSH-R signaling, and correcting active TED endpoints, including proptosis and diplopia. ${ }^{35,108}$ Modified from Douglas RS. Teprotumumab, an insulin-like growth factor-I receptor antagonist antibody, in the treatment of active thyroid eye disease: a focus on proptosis. Eye (Lond). 2019;33(2):183-198. Creative Commons License and Disclaimer available from: http://creativecommons.org/licenses/by/4.0/legalcode. ${ }^{2}$

Abbreviations: GD-IgG, Graves' disease immunoglobulins; IGF-IR, insulin-like growth factor-I receptor; TED, thyroid eye disease; TSH-R, thyroid-stimulating hormone receptor; TSI, thyroid-stimulating immunoglobulin.

placebo group at $6,12,18$, and 24 weeks (all $\mathrm{P}<0.001$ ), with $69 \%$ of teprotumumab-treated patients achieving the outcome at 24 weeks (vs $20 \%$ of placebo). ${ }^{108}$ Furthermore, the effect observed after 6 weeks was following only 2 infusions. ${ }^{108}$ Additionally, $71.4 \%$ of teprotumumab-treated patients (vs $20.0 \%$ of placebo-treated patients) had $\geq 2 \mathrm{~mm}$ reduction in proptosis at week $24(\mathrm{P}<0.001){ }^{2}$ The greatest improvement was seen in the more severely affected patients, ${ }^{2}$ with $40 \%$ (17/42) of patients receiving teprotumumab experiencing a $\geq 4 \mathrm{~mm}$ reduction in proptosis at week 24 vs $0(0 / 45)$ patients in the placebo group. ${ }^{108}$ To reduce the chances of variability in evaluation of 
proptosis, the same type of exophthalmometer was used at each study site and the same site observer completed each patient evaluation. Strikingly, this degree of amelioration in proptosis is consistent with that observed following surgical intervention. ${ }^{2,83,108}$

QoL was significantly improved vs placebo at each visit following teprotumumab treatment, as determined by the overall Graves' ophthalmopathy (GO)-QoL scores. ${ }^{108}$ In addition, a higher number of teprotumumab-treated patients had an improvement in subjectively evaluated diplopia, compared to placebo-treated patients. ${ }^{108}$ Teprotumumab continued to exert beneficial effects 7 weeks after the final infusion, with the number of patients with reduced CAS and proptosis continuing to increase. ${ }^{108}$ Furthermore, teprotumumab was well-tolerated and the majority of AEs were mild, well-controlled, and resolved without treatment. ${ }^{108}$ Hearing impairment was observed in $3(7 \%)$ teprotumumab-treated and 0 placebotreated patients. ${ }^{108}$ Hyperglycemia occurred in a small number of patients in both groups. In the teprotumumab-treated group, hyperglycemia was grade 1 in patients with no history of diabetes. ${ }^{108}$ In diabetic patients, hyperglycemia was grade 2 or 3 , and resolved with adjustment of diabetes medication. ${ }^{108}$ In the teprotumumab-treated patients, hyperglycemia was thought to be due to IGF-1R inhibition, although teprotumumab lacks affinity for the insulin receptor. ${ }^{108}$ Consequently, recommendations include close monitoring of diabetic patients treated with teprotumumab. ${ }^{108}$

The findings from the phase 2 trial were recently confirmed with the initial release of results from the phase 3 placebo-controlled trial, which indicated a significant reduction in the primary outcome, defined as the percentage of patients with $\mathrm{a} \geq 2-\mathrm{mm}$ reduction in proptosis at week 24 with teprotumumab vs placebo. ${ }^{109}$

\section{Conclusion}

TED was described over 60 years ago, ${ }^{47}$ but there have been few advancements in the effective therapeutic management of the disease since. ${ }^{2}$ Recent developments in the understanding of the molecular basis of TED have led to the development of targeted therapies, such as teprotumumab, which appears to regress the historically resistant progressive outcomes of muscle and fat expansion. ${ }^{2,108}$ The phase 2 findings, confirmed with the initial release of the phase 3 data, demonstrated dramatic improvement in proptosis and diplopia over the 24 -week study periods, and were similar to those obtained with surgery, indicating that there may be yet a viable therapeutic option for patients with active TED. ${ }^{2,108,109}$

\section{Abbreviations}

AE, adverse event; CAS, clinical activity score; GD, Graves' disease; IGF-1R, insulin-like growth factor-1 receptor; IL, interleukin; MMF, mycophenolate mofetil; MPA, mycophenolic acid; OR, orbital radiation; QoL, quality of life; TED, thyroid eye disease; TNF- $\alpha$, tumor necrosis factor alpha; TSH-R, thyroid-stimulating hormone receptor; TSI, thyroid stimulating immunoglobulins.

\section{Acknowledgments}

The authors would like to thank Robert J. Holt, PharmD, MBA; and Megan Francis-Sedlak, PhD, Medical Affairs, Horizon Therapeutics plc, for helpful discussions. Medical writing and editorial support were provided by MarieLouise Ricketts, $\mathrm{PhD}$; and Claire Daniele, $\mathrm{PhD}$, of AlphaBioCom, LLC, King of Prussia, PA. Support for preparation of this manuscript was provided by Horizon, Lake Forest, IL. The funder was not involved in writing the article or the decision to submit the article for publication.

\section{Disclosure}

Raymond S. Douglas is a consultant for Horizon Therapeutics, plc. The authors report no other conflicts of interest in this work.

\section{References}

1. Bartalena L, Baldeschi L, Boboridis K, et al. The 2016 European Thyroid Association/European group on Graves' orbitopathy guidelines for the management of graves' orbitopathy. Eur Thyroid $J$. 2016;5(1):9-26. doi:10.1159/000443828

2. Douglas RS. Teprotumumab, an insulin-like growth factor-1 receptor antagonist antibody, in the treatment of active thyroid eye disease: a focus on proptosis. Eye (Lond). 2019;33(2):183-198. doi:10.1038/s41433-018-0321-y

3. Smith TJ. New advances in understanding thyroid-associated ophthalmopathy and the potential role for insulin-like growth factor-I receptor. F1000Res. 2018;7:134. doi:10.12688/f1000research

4. Smith TJ, Hegedus L. Graves' disease. $N$ Engl J Med. 2016;375 (16):1552-1565. doi:10.1056/NEJMra1510030

5. Verity DH, Rose GE. Acute thyroid eye disease (TED): principles of medical and surgical management. Eye (Lond). 2013;27(3):308319. doi:10.1038/eye.2012.284

6. Kahaly GJ, Petrak F, Hardt J, Pitz S, Egle UT. Psychosocial morbidity of Graves' orbitopathy. Clin Endocrinol (Oxf). 2005;63 (4):395-402. doi:10.1111/j.1365-2265.2005.02352.x

7. Park JJ, Sullivan TJ, Mortimer RH, Wagenaar M, Perry-Keene DA. Assessing quality of life in Australian patients with Graves' ophthalmopathy. Br J Ophthalmol. 2004;88(1):75-78. doi:10.1136/bjo.88.1.75

8. Minakaran N, Ezra DG. Rituximab for thyroid-associated ophthalmopathy. Cochrane Database Syst Rev. 2013;5:CD009226.

9. Hamed Azzam S, Kang S, Salvi M, Ezra DG. Tocilizumab for thyroid eye disease. Cochrane Database Syst Rev. 2018;11:CD012984.

10. Douglas RS, Gupta S. The pathophysiology of thyroid eye disease: implications for immunotherapy. Curr Opin Ophthalmol. 2011;22 (5):385-390. doi:10.1097/ICU.0b013e3283499446 
11. Bothun ED, Scheurer RA, Harrison AR, Lee MS. Update on thyroid eye disease and management. Clin Ophthalmol. 2009;3:543-551. doi:10.2147/opth.s5228

12. Cyranska-Chyrek E, Olejarz M, Szczepanek-Parulska E, Stajgis P, Pioch A, Ruchala M. Severe unilateral orbitopathy in a patient with Hashimoto's thyroiditis - a case report. BMC Ophthalmol. 2019;19 (1):9. doi:10.1186/s12886-018-1018-5

13. Perros P, Neoh C, Dickinson J. Thyroid eye disease. Br Med J. 2009;338:b560. doi:10.1136/bmj.b902

14. Mohyi M, Smith TJ. IGF1 receptor and thyroid-associated ophthalmopathy. J Mol Endocrinol. 2018;61(1):T29-T43. doi:10.1530/ JME-17-0276

15. Sahli E, Gunduz K. Thyroid-associated ophthalmopathy. Turk $J$ Ophthalmol. 2017;47(2):94-105. doi:10.4274/tjo.80688

16. Gillespie EF, Smith TJ, Douglas RS. Thyroid eye disease: towards an evidence base for treatment in the 21st century. Curr Neurol Neurosci Rep. 2012;12(3):318-324. doi:10.1007/s11910-012-0256-9

17. Khoo DH, Eng PH, Ho SC, et al. Graves' ophthalmopathy in the absence of elevated free thyroxine and triiodothyronine levels: prevalence, natural history, and thyrotropin receptor antibody levels. Thyroid. 2000;10(12):1093-1100. doi:10.1089/thy.2000.10.1093

18. Perros P, Hegedus L, Bartalena L, et al. Graves' orbitopathy as a rare disease in Europe: a European Group on Graves' Orbitopathy (EUGOGO) position statement. Orphanet J Rare Dis. 2017;12 (1):72. doi:10.1186/s13023-017-0625-1

19. Bartley GB. The epidemiologic characteristics and clinical course of ophthalmopathy associated with autoimmune thyroid disease in Olmsted County, Minnesota. Trans Am Ophthalmol Soc. 1994;92:477-588.

20. Perros P, Zarkovic M, Azzolini C, et al. PREGO (presentation of Graves' orbitopathy) study: changes in referral patterns to European Group On Graves' Orbitopathy (EUGOGO) centres over the period from 2000 to 2012. Br J Ophthalmol. 2015;99 (11):1531-1535. doi:10.1136/bjophthalmol-2015-306733

21. Stan MN, Bahn RS. Risk factors for development or deterioration of Graves' ophthalmopathy. Thyroid. 2010;20(7):777-783. doi:10.1089/thy.2010.1634

22. Eckstein A, Quadbeck B, Mueller G, et al. Impact of smoking on the response to treatment of thyroid associated ophthalmopathy. $\mathrm{Br}$ J Ophthalmol. 2003;87(6):773-776. doi:10.1136/bjo.87.6.773

23. Roos JCP, Paulpandian V, Murthy R. Serial TSH-receptor antibody levels to guide the management of thyroid eye disease: the impact of smoking, immunosuppression, radio-iodine, and thyroidectomy. Eye (Lond). 2019;33(2):212-217. doi:10.1038/s41433-018-0242-9

24. Bartalena L, Marcocci C, Bogazzi F, et al. Relation between therapy for hyperthyroidism and the course of Graves' ophthalmopathy. $N$ Engl J Med. 1998;338(2):73-78. doi:10.1056/NEJM199801083 380201

25. Smith TJ. TSHR as a therapeutic target in Graves' disease. Expert Opin Ther Targets. 2017;21(4):427-432. doi:10.1080/14728222.2017.128 8215

26. Smith TJ, Janssen JA. Building the case for insulin-like growth factor receptor-I involvement in thyroid-associated ophthalmopathy. Front Endocrinol (Lausanne). 2017;7:167. doi:10.3389/ fendo.2016.00167

27. Tsui S, Naik V, Hoa N, et al. Evidence for an association between thyroid-stimulating hormone and insulin-like growth factor 1 receptors: a tale of two antigens implicated in Graves' disease. J Immunol. 2008;181(6):4397-4405. doi:10.4049/jimmunol.181.6.4397

28. Bahn RS, Dutton CM, Natt N, Joba W, Spitzweg C, Heufelder AE. Thyrotropin receptor expression in graves' orbital adipose/connective tissues: potential autoantigen in Graves' ophthalmopathy. $J$ Clin Endocrinol Metab. 1998;83(3):998-1002. doi:10.1210/jcem.83.3.4676

29. Weightman DR, Perros P, Sherif IH, Kendall-Taylor P. Autoantibodies to IGF-1 binding sites in thyroid associated ophthalmopathy. Autoimmunity. 1993;16(4):251-257.
30. Alsuhaibani AH, Nerad JA. Thyroid-associated orbitopathy. Semin Plast Surg. 2007;21(1):65-73. doi:10.1055/s-2007-967751

31. Smith TJ, Hegedus L, Douglas RS. Role of insulin-like growth factor-1 (IGF-1) pathway in the pathogenesis of Graves' orbitopathy. Best Pract Res Clin Endocrinol Metab. 2012;26(3):291-302. doi:10.1016/j.beem.2011.10.002

32. Krieger CC, Neumann S, Place RF, Marcus-Samuels B, Gershengorn MC. Bidirectional TSH and IGF-1 receptor cross talk mediates stimulation of hyaluronan secretion by Graves' disease immunoglobins. J Clin Endocrinol Metab. 2015;100(3):10711077. doi:10.1210/jc.2014-3566

33. Douglas RS, Gianoukakis AG, Kamat S, Smith TJ. Aberrant expression of the insulin-like growth factor-1 receptor by $\mathrm{T}$ cells from patients with Graves' disease may carry functional consequences for disease pathogenesis. $J$ Immunol. 2007;178(5):32813287. doi:10.4049/jimmunol.178.5.3281

34. Douglas RS, Naik V, Hwang CJ, et al. B cells from patients with Graves' disease aberrantly express the IGF-1 receptor: implications for disease pathogenesis. J Immunol. 2008;181(8):5768-5774. doi:10.4049/jimmunol.181.8.5768

35. Chen H, Mester T, Raychaudhuri N, et al. Teprotumumab, an IGF1R blocking monoclonal antibody inhibits TSH and IGF-1 action in fibrocytes. J Clin Endocrinol Metab. 2014;99(9):E1635-E1640. doi:10.1210/jc.2014-1580

36. Pritchard J, Horst N, Cruikshank W, Smith TJ. Igs from patients with Graves' disease induce the expression of T cell chemoattractants in their fibroblasts. $J$ Immunol. 2002;168(2):942-950. doi:10.4049/jimmunol.168.2.942

37. Smith TJ, Hoa N. Immunoglobulins from patients with Graves' disease induce hyaluronan synthesis in their orbital fibroblasts through the self-antigen, insulin-like growth factor-I receptor. $J$ Clin Endocrinol Metab. 2004;89(10):5076-5080. doi:10.1210/ jc. 2004-0716

38. Li Q, Ye H, Ding Y, et al. Clinical characteristics of moderate-tosevere thyroid associated ophthalmopathy in 354 Chinese cases. PLoS One. 2017;12(5):e0176064. doi:10.1371/journal.pone.0176064

39. Bartley GB, Fatourechi V, Kadrmas EF, et al. Clinical features of Graves' ophthalmopathy in an incidence cohort. Am J Ophthalmol. 1996;121(3):284-290. doi:10.1016/s0002-9394(14)70276-4

40. Albert D, Miller J, Azar D, Blodi B. Albert \& Jakobiec's Principles \& Practice of Ophthalmology. 3rd ed. Philadelphia, PA: Saunders; 2008.

41. Savar LM, Menghani RM, Chong KK, Chokron Garneau H, Goldberg RA. Eyebrow tissue expansion: an underappreciated entity in thyroid-associated orbitopathy. Arch Ophthalmol. 2012;130(12):1566-1569. doi:10.1001/archophthalmol.2012.2543

42. Kim BJ, Kazim M. Prominent premalar and cheek swelling: a sign of thyroid-associated orbitopathy. Ophthalmic Plast Reconstr Surg. 2006;22(6):457-460. doi:10.1097/01.iop.0000244972.03781.c6

43. Trobe JD, Glaser JS, Laflamme P. Dysthyroid optic neuropathy. clinical profile and rationale for management. Arch Ophthalmol. 1978;96(7):1199-1209. doi:10.1001/archopht.1978.03910060033 007

44. Hedges TR Jr, Scheie HG. Visual field defects in exophthalmos associated with thyroid disease. AMA Arch Ophthalmol. 1955;54 (6):885-892.

45. Neigel JM, Rootman J, Belkin RI, et al. Dysthyroid optic neuropathy. The crowded orbital apex syndrome. Ophthalmology. 1988;95(11):1515-1521. doi:10.1016/s0161-6420(88)32978-7

46. McKeag D, Lane C, Lazarus JH, et al. Clinical features of dysthyroid optic neuropathy: a European Group on Graves' Orbitopathy (EUGOGO) survey. $\mathrm{Br} \quad \mathrm{J}$ Ophthalmol. 2007;91(4):455-458. doi:10.1136/bjo.2006.094607

47. Rundle FF, Wilson CW. Development and course of exophthalmos and ophthalmoplegia in Graves' disease with special reference to the effect of thyroidectomy. Clin Sci. 1945;5(3-4):177-194. 
48. Selva D, Chen C, King G. Late reactivation of thyroid orbitopathy. Clin Experiment Ophthalmol. 2004;32(1):46-50. doi:10.1046/ j.1442-9071.2004.00756.x

49. Patel P, Khandji J, Kazim M. Recurrent thyroid eye disease. Ophthalmic Plast Reconstr Surg. 2015;31(6):445-448. doi:10.1097/IOP.0000000000000371

50. Baldeschi L, Lupetti A, Vu P, Wakelkamp IM, Prummel MF, Wiersinga WM. Reactivation of Graves' orbitopathy after rehabilitative orbital decompression. Ophthalmology. 2007;114(7):13951402. doi:10.1016/j.ophtha.2006.10.036

51. Shadpour JM, Menghani RM, Douglas RS, Goldberg RA, Tsirbas A. Reactivation of thyroid-associated orbitopathy after cataract surgery. Jpn J Ophthalmol. 2009;53(1):44 46. doi:10.1007/s10384-008-0607-x

52. Barrio-Barrio J, Sabater AL, Bonet-Farriol E, Velazquez-Villoria A, Galofre JC. Graves' ophthalmopathy: VISA versus EUGOGO classification, assessment, and management. J Ophthalmol. 2015;2015:249125.

53. Nicosia L, Reverberi C, Agolli L, et al. Orbital radiotherapy plus concomitant steroids in moderate-to-severe Graves' ophthalmopathy: good results after long-term follow-up. Int $J$ Endocrinol Metab. 2019;17(1):e84427.

54. Bartalena L, Pinchera A, Marcocci C. Management of Graves' ophthalmopathy: reality and perspectives. Endocr Rev. 2000;21 (2):168-199. doi:10.1210/edrv.21.2.0393

55. Tanda ML, Bartalena L. Efficacy and safety of orbital radiotherapy for Graves' orbitopathy. J Clin Endocrinol Metab. 2012;97 (11):3857-3865. doi:10.1210/jc.2012-2758

56. Kahaly G, Beyer J. Immunosuppressant therapy of thyroid eye disease. Klin Wochenschr. 1988;66(21):1049-1059. doi:10.1007/bf01711917

57. Gorman CA, Garrity JA, Fatourechi V, et al. A prospective, randomized, double-blind, placebo-controlled study of orbital radiotherapy for Graves' ophthalmopathy. Ophthalmology. 2001;108 (9):1523-1534. doi:10.1016/s0161-6420(01)00632-7

58. Mourits MP, van Kempen-Harteveld ML, Garcia MB, Koppeschaar HP, Tick L, Terwee CB. Radiotherapy for Graves' orbitopathy: randomised placebo-controlled study. Lancet (London, England). 2000;355(9214):1505-1509. doi:10.1016/S0140-6736(00)02165-6

59. Prummel MF, Terwee CB, Gerding $\mathrm{MN}$, et al. A randomized controlled trial of orbital radiotherapy versus sham irradiation in patients with mild Graves' ophthalmopathy. J Clin Endocrinol Metab. 2004;89(1):15-20. doi:10.1210/jc.2003-030809

60. Bartalena L, Marcocci C, Chiovato L, et al. Orbital cobalt irradiation combined with systemic corticosteroids for Graves' ophthalmopathy: comparison with systemic corticosteroids alone. J Clin Endocrinol Metab. 1983;56(6):1139-1144. doi:10.1210/jcem-56-61139

61. Ng CM, Yuen HK, Choi KL, et al. Combined orbital irradiation and systemic steroids compared with systemic steroids alone in the management of moderate-to-severe Graves' ophthalmopathy: a preliminary study. Hong Kong Med J. 2005;11(5):322-330.

62. Marcocci C, Bartalena L, Bogazzi F, Bruno-Bossio G, Lepri A, Pinchera A. Orbital radiotherapy combined with high dose systemic glucocorticoids for Graves' ophthalmopathy is more effective than radiotherapy alone: results of a prospective randomized study. $J$ Endocrinol Invest. 1991;14(10):853-860. doi:10.1007/BF03347943

63. Prummel MF, Mourits MP, Blank L, Berghout A, Koornneef L, Wiersinga WM. Randomized double-blind trial of prednisone versus radiotherapy in Graves' ophthalmopathy. Lancet (London, England). 1993;342(8877):949-954. doi:10.1016/0140-6736(93)92001-a

64. Bradley EA, Gower EW, Bradley DJ, et al. Orbital radiation for Graves ophthalmopathy: a report by the American Academy of ophthalmology. Ophthalmology. 2008;115(2):398-409. doi:10.1016/ j.ophtha.2007.10.028

65. Bartalena L, Krassas GE, Wiersinga W, et al. Efficacy and safety of three different cumulative doses of intravenous methylprednisolone for moderate to severe and active Graves' orbitopathy. J Clin Endocrinol Metab. 2012;97(12):4454 4463. doi:10.1210/jc.2012-2389
66. van Geest RJ, Sasim IV, Koppeschaar HP, et al. Methylprednisolone pulse therapy for patients with moderately severe Graves' orbitopathy: a prospective, randomized, placebocontrolled study. Eur J Endocrinol. 2008;158(2):229-237. doi:10.1530/EJE-07-0558

67. Ebner R, Devoto MH, Weil D, et al. Treatment of thyroid associated ophthalmopathy with periocular injections of triamcinolone. $\mathrm{Br} \mathrm{J}$ Ophthalmol. 2004;88(11):1380-1386. doi:10.1136/bjo.2004.046193

68. Riedl M, Kuhn A, Kramer I, Kolbe E, Kahaly GJ. Prospective, systematically recorded mycophenolate safety data in Graves' orbitopathy. $J$ Endocrinol Invest. 2016;39(6):687-694. doi:10.1007/s40618-016-0441-9

69. Ye X, Bo X, Hu X, et al. Efficacy and safety of mycophenolate mofetil in patients with active moderate-to-severe Graves' orbitopathy. Clin Endocrinol (Oxf). 2017;86(2):247-255. doi:10.1111/cen.13170

70. Kahaly GJ, Riedl M, Konig J, et al. Mycophenolate plus methylprednisolone versus methylprednisolone alone in active, moderate-to-severe Graves' orbitopathy (MINGO): a randomised, observer-masked, multicentre trial. Lancet Diabetes Endocrinol. 2018;6(4):287-298. doi:10.1016/S2213-8587(18)30020-2

71. Prummel MF, Mourits MP, Berghout A, et al. Prednisone and cyclosporine in the treatment of severe Graves' ophthalmopathy. $N$ Engl J Med. 1989;321(20):1353-1359. doi:10.1056/NEJM198911163212002

72. Kahaly G, Schrezenmeir J, Krause U, et al. Ciclosporin and prednisone v. prednisone in treatment of Graves' ophthalmopathy: a controlled, randomized and prospective study. Eur J Clin Invest. 1986;16(5):415-422. doi:10.1111/j.1365-2362.1986.tb01016.x

73. Antonelli A, Saracino A, Alberti B, et al. High-dose intravenous immunoglobulin treatment in Graves' ophthalmopathy. Acta Endocrinol (Copenh). 1992;126(1):13-23. doi:10.1530/acta.0.1260013

74. Kahaly G, Pitz S, Muller-Forell W, Hommel G. Randomized trial of intravenous immunoglobulins versus prednisolone in Graves' ophthalmopathy. Clin Exp Immunol. 1996;106(2):197-202. doi:10.1046/j.1365-2249.1996.d01-854.x

75. Perros P, Weightman DR, Crombie AL, Kendall-Taylor P. Azathioprine in the treatment of thyroid-associated ophthalmopathy. Acta Endocrinol (Copenh). 1990;122(1):8-12. doi:10.1530/acta.0.1220008

76. Kahaly G, Lieb W, Muller-Forell W, et al. Ciamexone in endocrine orbitopathy. A randomized double-blind, placebo-controlled study. Acta Endocrinol (Copenh). 1990;122(1):13-21. doi:10.1530/acta.0.1220013

77. Dickinson AJ, Vaidya B, Miller M, et al. Double-blind, placebocontrolled trial of octreotide long-acting repeatable (LAR) in thyroid-associated ophthalmopathy. J Clin Endocrinol Metab. 2004;89 (12):5910-5915. doi:10.1210/jc.2004-0697

78. Wemeau JL, Caron P, Beckers A, et al. Octreotide (long-acting release formulation) treatment in patients with Graves' orbitopathy: clinical results of a four-month, randomized, placebo-controlled, double-blind study. J Clin Endocrinol Metab. 2005;90(2):841-848. doi:10.1210/jc.2004-1334

79. Chang TC, Liao SL. Slow-release lanreotide in Graves' ophthalmopathy: a double-blind randomized, placebo-controlled clinical trial. $J$ Endocrinol Invest. 2006;29(5):413-422. doi:10.1007/BF03344124

80. Stan MN, Garrity JA, Carranza Leon BG, Prabin T, Bradley EA, Bahn RS. Randomized controlled trial of rituximab in patients with Graves' orbitopathy. J Clin Endocrinol Metab. 2015;100(2):432441. doi:10.1210/jc.2014-2572

81. Fichter N, Guthoff RF, Schittkowski MP. Orbital decompression in thyroid eye disease. ISRN Ophthalmol. 2012;2012:739236. doi:10.5402/2012/739236

82. Victores AJ, Takashima M. Thyroid eye disease: optic neuropathy and orbital decompression. Int Ophthalmol Clin. 2016;56(1):69-79. doi:10.1097/IIO.0000000000000101

83. Rootman DB, Golan S, Pavlovich P, Rootman J. Postoperative changes in strabismus, ductions, exophthalmometry, and eyelid retraction after orbital decompression for thyroid orbitopathy. Ophthalmic Plast Reconstr Surg. 2017;33(4):289-293. doi:10.1097/IOP.000 0000000000758 
84. Yeatts RP. Quality of life in patients with Graves ophthalmopathy. Trans Am Ophthalmol Soc. 2005;103:368-411.

85. Jackson JL. Nonsurgical management of diplopia after orbital decompression surgery. Am Orthopt J. 2012;62:29-33.

86. Frueh BR, Musch DC, Garber FW. Lid retraction and levator aponeurosis defects in Graves' eye disease. Ophthalmic Surg. 1986;17(4):216-220.

87. Ivekovic R, Novak-Laus K, Tedeschi-Reiner E, Masnec-Paskvalin S, Saric D, Mandic Z. Full-thickeness anterior blepharotomy and transpalpebral fat decompression in Graves' orbitopathy. Coll Antropol. 2005;29(Suppl 1):33-36.

88. Dixon R. The surgical management of thyroid-related upper eyelid retraction. Ophthalmology. 1982;89(1):52-57. doi:10.1016/s01616420(82)34861-7

89. Ribeiro SF, Shekhovtsova M, Duarte AF, Velasco Cruz AA. Graves lower eyelid retraction. Ophthalmic Plast Reconstr Surg. 2016;32 (3):161-169. doi:10.1097/IOP.0000000000000613

90. Gardner TA, Kennerdell JS, Buerger GF. Treatment of dysthyroid lower lid retraction with autogenous tarsus transplants. Ophthalmic Plast Reconstr Surg. 1992;8(1):26-31.

91. Oestreicher JH, Pang NK, Liao W. Treatment of lower eyelid retraction by retractor release and posterior lamellar grafting: an analysis of 659 eyelids in 400 patients. Ophthalmic Plast Reconstr Surg. 2008;24(3):207-212. doi:10.1097/IOP.0b013e3181706840

92. Genere N, Stan MN. Current and emerging treatment strategies for Graves' orbitopathy. Drugs. 2019;79(2):109-124. doi:10.1007/ s40265-018-1045-9

93. Planck T, Shahida B, Parikh H, et al. Smoking induces overexpression of immediate early genes in active Graves' ophthalmopathy. Thyroid. 2014;24(10):1524-1532. doi:10.1089/thy.2014.0153

94. Nita M, Grzybowski A. Smoking and eye pathologies. a systemic review. part ii. retina diseases, uveitis, optic neuropathies, thyroidassociated orbitopathy. Curr Pharm Des. 2017;23(4):639-654. doi:10.2174/1381612823666170111095723

95. Marcocci C, Kahaly GJ, Krassas GE, et al. Selenium and the course of mild Graves' orbitopathy. N Engl J Med. 2011;364(20):19201931. doi:10.1056/NEJMoa1012985

96. Burch HB, Lahiri S, Bahn RS, Barnes S. Superoxide radical production stimulates retroocular fibroblast proliferation in Graves' ophthalmopathy. Exp Eye Res. 1997;65(2):311-316. doi:10.1006/ exer.1997.0353

97. Bouzas EA, Karadimas P, Mastorakos G, Koutras DA. Antioxidant agents in the treatment of Graves' ophthalmopathy. Am J Ophthalmol. 2000;129(5):618-622. doi:10.1016/s0002-9394(00)00359-7

98. Smolen JS, Beaulieu A, Rubbert-Roth A, et al. Effect of interleukin-6 receptor inhibition with tocilizumab in patients with rheumatoid arthritis (OPTION study): a double-blind, placebo-controlled, randomised trial. Lancet (London, England). 2008;371(9617):987997. doi:10.1016/S0140-6736(08)60453-5

99. ACTEMRA ${ }^{\circledR}$ (tocilizumab) [package insert] Injection, for Intravenous or Subcutaneous Use. Full Prescribing Information. South San Francisco, CA: Genentech, Inc.; 2019.
100. Slowik M, Urbaniak-Kujda D, Bohdanowicz-Pawlak A, et al. CD8 +CD28-lymphocytes in peripheral blood and serum concentrations of soluble interleukin 6 receptor are increased in patients with Graves' orbitopathy and correlate with disease activity. Endocr Res. 2012;37 (2):89-95. doi:10.3109/07435800.2011.635622

101. Russell DJ, Wagner LH, Seiff SR. Tocilizumab as a steroid sparing agent for the treatment of Graves' orbitopathy. Am J Ophthalmol Case Rep. 2017;7:146-148. doi:10.1016/j.ajoc.2017.07.001

102. Perez-Moreiras JV, Gomez-Reino JJ, Maneiro JR, et al. Efficacy of tocilizumab in patients with moderate-to-severe corticosteroid-resistant Graves orbitopathy: a randomized clinical trial. Am J Ophthalmol. 2018;195:181-190. doi:10.1016/j.ajo.2018.07.038

103. Ayabe R, Rootman DB, Hwang CJ, Ben-Artzi A, Goldberg R. Adalimumab as steroid-sparing treatment of inflammatory-stage thyroid eye disease. Ophthalmic Plast Reconstr Surg. 2014;30 (5):415-419. doi:10.1097/IOP.0000000000000211

104. Durrani OM, Reuser TQ, Murray PI. Infliximab: a novel treatment for sight-threatening thyroid associated ophthalmopathy. Orbit. 2005;24(2):117-119. doi:10.1080/01676830590912562

105. Rajaii F, McCoy AN, Smith TJ. Cytokines are both villains and potential therapeutic targets in thyroid-associated ophthalmopathy: from bench to bedside. Expert Rev Ophthalmol. 2014;9(3):227234. doi:10.1586/17469899.2014.917960

106. RITUXAN ${ }^{\circledR}$ (rituximab) [package insert] Injection, for Intravenous Use. Full Prescribing Information. South San Francisco, CA: Genentech, Inc.; 2019.

107. Salvi M, Vannucchi G, Curro N, et al. Efficacy of B-cell targeted therapy with rituximab in patients with active moderate to severe Graves' orbitopathy: a randomized controlled study. J Clin Endocrinol Metab. 2015;100(2):422-431. doi:10.1210/jc.2014-3014

108. Smith TJ, Kahaly GJ, Ezra DG, et al. Teprotumumab for ThyroidAssociated ophthalmopathy. N Engl J Med. 2017;376(18):17481761. doi:10.1056/NEJMoa1614949

109. Douglas RS, Sile S, Thompson EHZ, et al. Teprotumumab treatment effect on proptosis in patients with active thyroid eye disease: results from a phase 3 , randomized, double-masked, placebo-controlled, parallel-group, multicenter study. Proceedings of the American Association of clinical endocrinologists. Endocr Pract. 2019;25(Supplement 1). doi:10.4158/EP-2018-0405

110. Bartley GB. Rundle and his curve. Arch Ophthalmol. 2011;129 (3):356-358. doi:10.1001/archophthalmol.2011.29

111. Zang S, Ponto KA, Kahaly GJ. Clinical review:Intravenous glucocorticoids for Graves' orbitopathy: efficacy and morbidity. J Clin Endocrinol Metab. 2011;96:320-332.

112. Marcocci C, Bartalena L, Tanda ML, Manetti L, Dell'Unto E, Rocchi R, Barbesino G, Mazzi B, Bartolomei MP, Lepri P, Cartei F, Nardi M, Pinchera A. Comparison of the effectiveness and tolerability of intravenous or oral glucocorticoids associated with orbital radiotherapy in the management of severe Graves' ophthalmopathy: results of a prospective, single-blind, randomized study. $J$ Clin Endocrinol Metab. 2001;(86):3562-3567.

Therapeutics and Clinical Risk Management

\section{Dovepress}

\section{Publish your work in this journal}

Therapeutics and Clinical Risk Management is an international, peerreviewed journal of clinical therapeutics and risk management, focusing on concise rapid reporting of clinical studies in all therapeutic areas, outcomes, safety, and programs for the effective, safe, and sustained use of medicines. This journal is indexed on PubMed Central, CAS,
EMBase, Scopus and the Elsevier Bibliographic databases. The manuscript management system is completely online and includes a very quick and fair peer-review system, which is all easy to use. Visit http://www.dovepress.com/testimonials.php to read real quotes from published authors. 